

\section{SUBALTERNIDADE FEMININA: VIOLÊNCIA CONTRA A MULHER EM O OUTRO PÉ DA SEREIA, DE MIA COUTO}

\author{
Joseana Stringini da Rosa ${ }^{1}$ \\ Universidade Federal de Santa Maria (PPGL / UFSM). \\ (joseana.stringini@gmail.com)
}

\begin{abstract}
Resumo: O presente trabalho propõe uma análise da obra O outro pé da sereia, de Mia Couto, tendo em vista questões como a força, o poder, a violência atuando nas personagens femininas. O romance, publicado em 2006 no Brasil e em Portugal, apresenta tradições e leis que põem a mulher, muitas vezes, em um segundo plano, como subalterna ao homem. A partir da narrativa, objetiva-se dar ênfase na questão da violência, seja ela física, psicológica, sexual, simbólica e/ou violência de gênero que tem como ponto-alvo a mulher. Para a discussão teórica, busca-se pressupostos que possam dar conta da temática, trazendo para a discussão autores como Norberto Bobbio, Wolfgang Sofsky e Pierre Bourdieu, visto que em uma sociedade que tem como sistema vigente o patriarcado, questões em torno da mulher como a opressão, a submissão, a subalternidade e o silenciamento de vozes se fazem presentes. Como resultado inicial, tem-se a visualização dos diferentes tipos de violência no contexto narrativo.
\end{abstract}

Palavras-chave: Subalternidade; Violência; Personagens femininas; Mia Couto.

Abstract: The present work proposes an analysis of Mia Couto 's "O outro pé da sereia", considering issues such as strength, power and violence acting on the female characters. The novel, published in 2006 in Brazil and Portugal, presents traditions and laws that put women, often, in the background, as subaltern to the man. From the narrative, it is aimed to emphasize the issue of violence, be it physical, psychological, sexual, symbolic and / or about gender violence that targets women. In the theoretical discussion, we search for assumptions that can account for the subject by bringing to the discussion authors such as Norberto Bobbio, Wolfgang Sofsky and Pierre Bourdieu. This choice is justfied, because in society that has patriarchy as its current system, issues around women as oppression, subordination, subordination, and voicelessness make themselves presente and relevant. As an initial result, we have the visualization of the different types of violence in the narrative context.

Keywords: Subalternity; Violence; Female characters; Mia Couto.

Resumen: El presente trabajo propone un análisis de la obra $O$ outro pé da sereia, de Mia Couto, considerando cuestiones como la fuerza, el poder y la violencia actuando en los personajes femeninos. La novela, publicada en 2006 en Brasil y en Portugal, presenta tradiciones y leyes que ponen la mujer, muchas veces, en un segundo plano, como subalterna al hombre. A partir de la narrativa, se objetiva dar énfasis a la cuestión de la violencia, sea la física, sea la psicológica, sexual, simbólica y/o la violencia de género que se direcciona a la mujer. Para la discusión teórica, se buscan los presupuestos que puedan dar cuenta de la temática, dialogando con autores como Norberto Bobbio, Wolfgang Sofsky y Pierre Bourdieu, ya que en una sociedad que tiene como sistema vigente el patriarcado, cuestiones acerca de la mujer como la opresión, la sumisión, la subalternidad y el silenciamiento de voces se hacen presentes. Como resultado inicial, se tiene la visualización de los diferentes tipos de violencia en el contexto narrativo.

Palabras-clave: Subalternidad; Violencia; Personajes femeninos, Mia Couto.

\footnotetext{
1 Mestra em Letras pelo Programa de Pós-Graduação em Letras da Universidade Federal de Santa Maria (PPGL/UFSM). Graduada em Comunicação Social: Jornalismo pela Universidade Franciscana (UFN).
} 


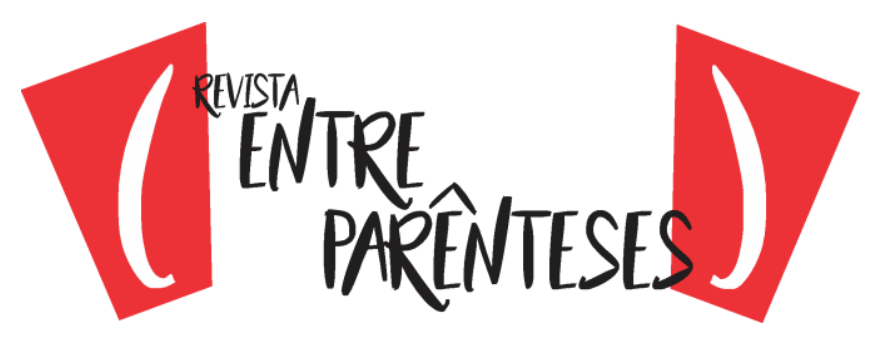

\section{Introdução}

Diariamente são noticiados casos de violência extrema e, através dos veículos de comunicação, invade, em nossas casas, uma espetacularização de crimes bárbaros motivados por disputas territoriais, vingança, busca de poder, muitos desses por motivos passionais. Vários crimes, como apresenta Sofsky, são motivados pela própria violência, como os casos envolvendo a tortura ou a execução, que tem como meio e fim a própria violência.

Na literatura, o tema da violência também se faz presente. Muitas narrativas criam, inclusive, uma realidade muito próxima ao mundo real, tão conhecido pelo leitor. Em O outro pé da sereia, de Mia Couto, há a presença de temáticas como as questões de gênero, em que a mulher é renegada a um segundo plano, como um ser inferior, sendo natural/tradicional impor a esse corpo uma normatividade. Normatividade essa que trata o feminino como submisso e subalterno a uma dominação masculina, determinando, assim, o silenciamento e sujeitando a mulher a uma obediência constante.

Ao analisar a obra em questão, é possível perceber diferentes tipos de violência. Pode-se abordar a questão da violência da colonização, visto que a obra em análise se trata de uma obra de Moçambique, país que foi colônia de Portugal, tendo a sua independência somente em 1975. Ao tratar da mulher na sociedade na qual se insere, há ainda uma dupla violência, uma dupla marginalização, sofrida tanto pela colonização quanto pelo masculino. O objetivo do trabalho é focar na violência que tem como ponto-alvo a mulher, pretendendo-se, assim, analisar a violência física, sexual, psicológica, simbólica, bem como a violência de gênero, que atacam o feminino.

Como objeto de análise, tem-se a obra O outro pé da sereia, de Mia Couto, publicada em 2006 em Portugal e no Brasil. Abordar-se-á como os diferentes tipos de violência, de agressão e de dominação atuam nas personagens femininas, trazendo 


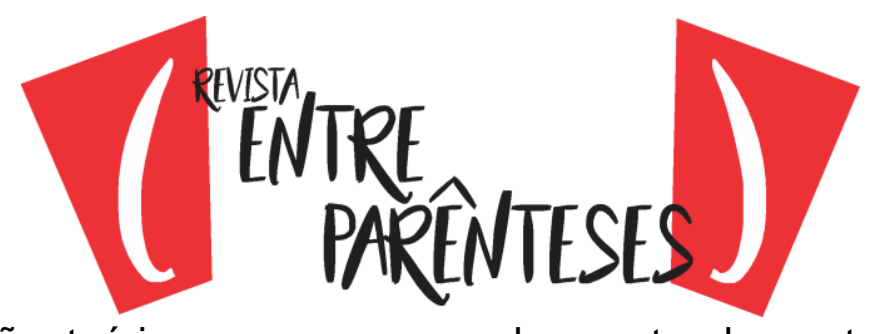

para a discussão teóricos que possam dar conta dessa temática central como Norberto Bobbio, Wolfgang Sofsky e Pierre Bourdieu.

Inicialmente, o presente artigo busca apresentar pressupostos teóricos que possam dar conta da questão da violência e suas ramificações para em seguida apresentar o corpus do trabalho. Por meio da análise da obra, busca-se demonstrar, através de passagens da narrativa, a força, a dominação, o poder e a violência atuando sobre o feminino.

\section{A violência a partir de pressupostos teóricos}

Tzvetan Todorov em seu livro A literatura em perigo (2010) apresenta a seguinte afirmação: "a literatura não nasce no vazio, mas no centro de um conjunto de discursos vivos, compartilhando com eles numerosas características" (TODOROV, 2010, p.22). Visto que a literatura não fala somente da literatura, mas também do mundo (real), pode-se encontrar narrativas ficcionais que se assemelham à vida real, ou vidas reais que imitam as ficções. As estatísticas de violência contra a mulher comprovam a situação real, tanto no Brasil, quanto em Moçambique, e não é por acaso que essa temática também pode ser percebida na literatura.

A violência contra as populações marginalizadas se faz presente e nesse quadro inserem-se as mulheres. Vítimas de uma cultura em que o patriarcalismo, o machismo, o poder, a força, imperam sobre os corpos femininos, e em que algumas tradições e alguns costumes são, muitas vezes, mantidos como naturais. O homem, neste contexto, apresenta-se como o catalisador dessa função dominadora, utilizando da força e da violência, seja ela física, sexual, psicológica e/ou simbólica, tornando, assim, a mulher em um ser submisso e reafirmando uma cultura normativa do homem como o "macho", forte, e a mulher, "sexo frágil". Portanto, se faz importante também a não dissociação da questão de gênero nessas discussões, visto que há a inserção, em um contexto histórico-cultural, tanto do homem, quanto da mulher em uma cultura que tenta tratar como natural/tradicional algumas questões. 


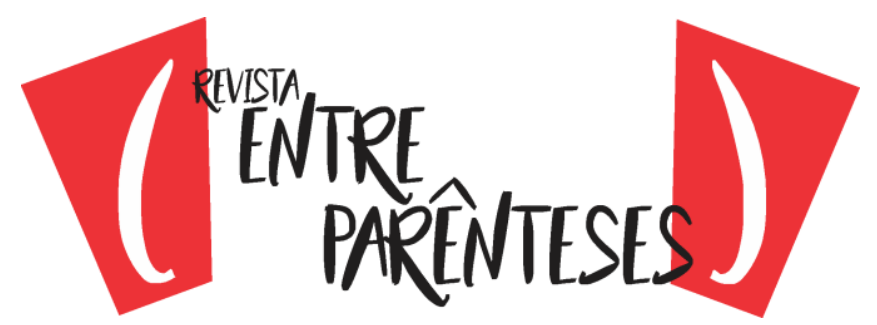

Os tipos de violência que se pretende abordar aqui estão ligados às agressões sofridas pelas mulheres e essas podem ser tanto física, psicológica, sexual e/ou simbólica. Para Norberto Bobbio, a necessidade de diferenciar a violência de poder, por exemplo, e de buscar as características próprias de cada "categoria" é ressaltada pois:

o uso indiscriminado do termo Violência, designando todas estas relações de poder, além das intervenções físicas, produz o grave dano de colocar, na mesma categoria, relações que são muito diversas entre si pelos caracteres estruturais, pelas funções e pelos efeitos, consequentemente provocando mais confusão do que clareza (BOBBIO, 2007, p. 1293).

Bobbio classifica o poder de forma diferente da categorização da violência, pois com o poder, intervêm-se sobre a vontade do outro, obtendo-se tanto uma ação como uma omissão, "tanto um acreditar como um desacreditar". Já com a violência, ao se intervir sobre o corpo, obtêm-se uma omissão: "imobilizando ou prendendo a vítima podemos impedi-la de realizar qualquer ação socialmente relevante, mas alterando o estado físico do outro não se pode obrigá-lo a fazer nada de socialmente relevante" (2007, p. 1292). Segundo o autor, pode haver o emprego de intervenções físicas como um meio para exercer o poder ou aumentá-lo, mas classificam-se em distinção:

Entendido no sentido puramente descritivo, o termo Violência pode considerar-se substancialmente sinônimo de força. Ele, porém, distingue-se de maneira precisa da noção de "poder". O poder é a modificação da conduta do indivíduo ou grupo, dotada de um mínimo de vontade própria. A Violência é a alteração danosa do estado físico de indivíduos ou grupos. O poder muda a vontade do outro; a Violência, o estado do corpo ou de suas possibilidades ambientais e instrumentais (BOBBIO, 2007, 1292).

Essas relações e diferenciações entre violência e poder podem ser encontradas no romance moçambicano, objeto de análise do presente trabalho. Este intercala em sua história passado e presente, e, portanto, reconstrói ficcionalmente um período da história do país que viveu sob o domínio de Portugal. Além da 


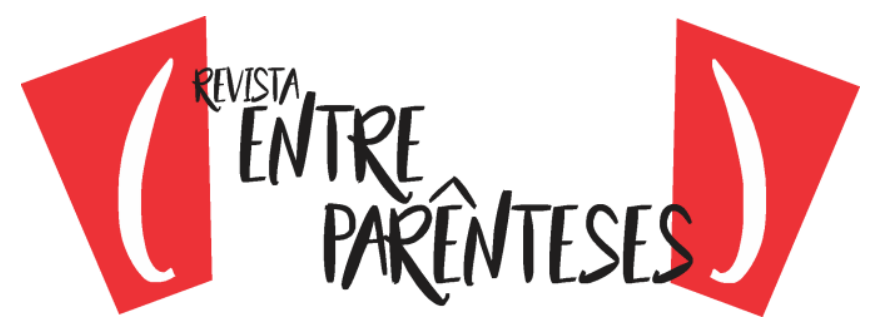

sociedade manter um sistema patriarcal e impor uma normatividade em relação à algumas tradições no que diz respeito à mulher, pode-se falar em uma dupla-violência ou uma dupla-marginalização, pois além das regras impostas à mulher pelo homem, há a violência imposta pela colonização. Em O local da cultura, Homi Bhabha (2013) afirma que: "Os olhos do homem branco destroçam o corpo do homem negro e nesse ato de violência epistemológica seu próprio quadro de referência é transgredido, seu campo de visão perturbado" (BHABHA, 2013, p. 80). Portanto, há também uma violência no processo de colonização e na relação colonizador/colonizado.

Em relação ao poder e à violência, Wolfgang Sofsky, em O tratado sobre la violencia (2006) busca no exemplo de um mito as origens da violência, que segundo ele, está diretamente ligada à conquista de poder. Sofsky (2006) traz uma história que envolve uma afinidade com as ideologias políticas e que não descreve o fim da violência, mas as mudanças que ela sofre com o decorrer do tempo. Há a presença de um círculo vicioso da violência: a tentativa de se combater a violência se dá com mais violência e o que move os homens a se unirem não é o impulso por uma sociabilidade, nem as necessidades envolvendo trabalho, mas, sim, a violência. Segundo Sofsky (2006), "A guerra de todos contra todos não consiste em um perpétuo banho de sangue, mas em um medo perpétuo a esse estado" (SOFSKY, 2006, p. 9)"2.

Pierre Bourdieu, em $A$ dominação masculina (2016), retrata um tipo de violência da qual ele chama de simbólica, que, segundo ele, é suave, insensível e invisível as suas próprias vítimas, que são exercidas por vias simbólicas da comunicação e do conhecimento, vista como aceitáveis ou até mesmo como naturais. Bourdieu se utiliza de uma passagem de Virginia Woolf, que trata dessas relações como "o poder hipnótico da dominação" para exemplificar essa demarcação de território imposta pelo homem e que impede a circulação da mulher:

Inevitavelmente, nós consideramos a sociedade um lugar de conspiração, que engole o irmão que muitas de nós temos razões de respeitar na vida privada, e impõe em seu lugar um macho monstruoso, de voz tonitruante, de pulso rude; que, de forma pueril,

\footnotetext{
2 Tradução livre para: "La guerra de todos contra todos no consiste en un perpetuo baño de sangre, sino en el miedo perpetuo a ese estado" (SOFSKY, 2006, p. 9).
} 


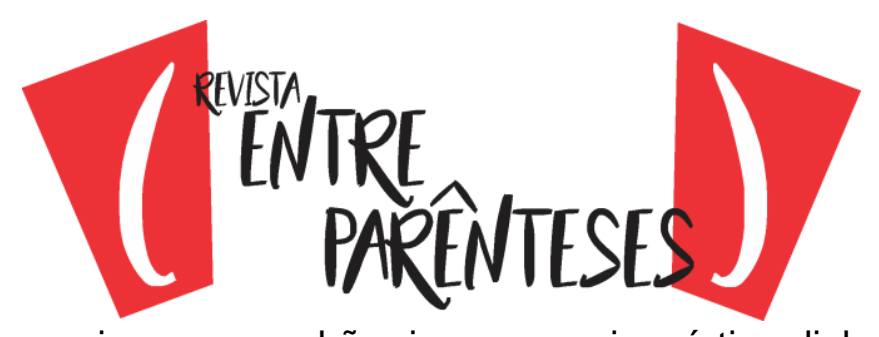

inscreve no chão signos com giz, místicas linhas de demarcação, entre as quais os seres humanos ficam fixados, rígidos, separados, artificiais. Lugares em que, ornado de ouro ou de púrpura, enfeitados de plumas como um selvagem, ele realiza seus ritos místicos e usufrui dos prazeres suspeitos do poder e da dominação, enquanto nós, 'suas' mulheres, nos vemos fechadas na casa da família, sem que nos seja dado participar de nenhuma das numerosas sociedades de que se compõe a sociedade (WOOLF apud BOURDIEU, 2016, p. 12).

Ao tratar desse "macho monstruoso", retoma-se Sofsky, que ao se referir às atrocidades cometidas pelos homens, torna-se comum dizer que se trata de um monstro ou obra de um diabo, porém, o autor salienta o não esquecimento de que: "o crime é obra humana, é algo especificamente do homem. As bestas mais ferozes não cometem tais monstruosidades. Somente o homem é capaz dos piores atos" (SOFSKY, 2006, p. 46)".

Tidos como monstruosos ou não, mas claramente alicerçados na vida, especificamente, do humano, a violência física, sexual, psicológica, simbólica, praticadas contra a mulher, configuram-se também como formas de violência de gênero contra essa. Por violência de gênero se entende como qualquer tipo de agressão que tenha como finalidade a organização social dos sexos e que impõe forças contra a condição de sexo ou orientação sexual, tendo em vista um conceito de gênero construído socialmente (e discriminatório) em que a diferenciação entre homens e mulheres dá-se como biologicamente e, portanto, naturais.

Sobre a discussão em torno de gênero, tem-se, conforme aponta Judith Butler, uma problemática na forma como são atribuídas noções de gênero na sociedade, e para isso, torna-se relevante desvincular o corpo de uma vitimização biológica, não como sendo resultado de uma ciência da anatomia, como uma natureza fixa do corpo. Também não se trata de generificar, de reduzir o corpo à classificações e enquadramentos, mas de lidar com todas as suas potencialidades. Para Butler,

O gênero não deve ser construído como uma identidade estável ou um locus de ação do qual decorrem vários atos; em vez disso, o

\footnotetext{
${ }^{3}$ Tradução livre para: "El crimen es obra humana, es algo específicamente humano. Las bestias más feroces no cometen monstruosidades. Sólo el hombre es capaz de los peores actos" (SOFSKY, 2006, p. 46).
} 


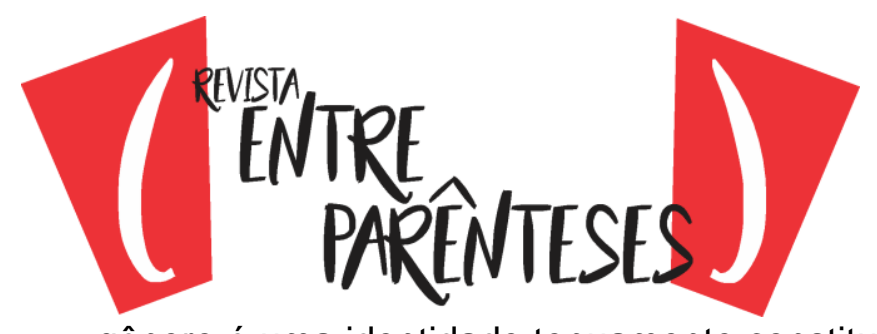

gênero é uma identidade tenuamente constituída no tempo, instituído num espaço externo por meio de uma repetição estilizada de atos. $\mathrm{O}$ efeito do gênero se produz pela estilização do corpo e deve ser entendido consequentemente, como a forma corriqueira pela qual os gestos, movimentos e estilos corporais de vários tipos constituem a ilusão de um eu permanentemente marcado pelo gênero. Essa formulação tira a concepção do gênero do solo de um modelo substancial da identidade, deslocando-a para um outro que requer concebê-lo como uma temporalidade social constituída (BUTLER, 2016, p. 242-244).

Tanto homens quanto mulheres podem sofrer esse tipo de violência, porém, inseridos em uma sociedade enraizada em uma cultura "machista" com resquícios de um patriarcalismo, são mulheres e homossexuais os mais atingidos. Como produto social e naturalizado, segundo Bourdieu, a violência simbólica:

\begin{abstract}
institui-se por meio da adesão que o dominado não pode deixar de conceder ao dominador (logo, à dominação), uma vez que ele não dispõe para pensá-lo ou pensar a si próprio, ou melhor, para pensar sua relação com ele, senão de instrumentos de conhecimento que ambos tểm em comum e que, não sendo senão a forma incorporada da relação de dominação, mostram esta relação como natural; ou, em outros termos, que os esquemas que ele mobiliza para se perceber e se avaliar ou para perceber e avaliar o dominador são o produto da incorporação de classificações, assim naturalizadas, das quais seu ser social é o produto (BOURDIEU, 2016, p. 45).
\end{abstract}

Na discussão sobre a dominação de corpos, Michel Foucault (2012), em seu livro Vigiar e Punir explicita sobre a noção da docilidade de corpos. Um corpo dócil é um corpo que pode ser submetido, utilizado, transformado e aperfeiçoado em fórmulas gerais de dominação:

Em qualquer sociedade, o corpo está preso no interior de poderes muito apertados, que the impõem limitações, proibições ou obrigações. Muitas coisas, entretanto, são novas nessas técnicas [...] métodos que permitem o controle minucioso das operações do corpo, que realizam a sujeição constante de suas forças e lhes impõem uma relação de docilidade-utilidade, são o que podemos chamar as "disciplinas". Muitos processos disciplinares existiam há muito tempo: nos conventos, nos exércitos, nas oficinas também. Mas as disciplinas se tornaram no decorrer dos séculos XVII e XVIII fórmulas gerais de dominação (FOUCAULT, 2012, p. 132-133). 


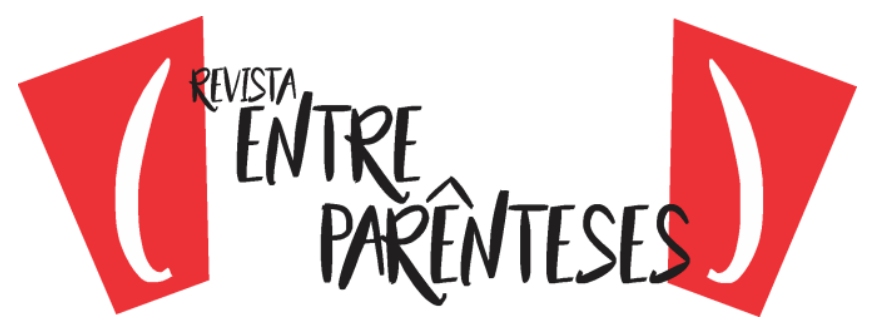

A violência física, com a presença de agressões contra o corpo, a violência sexual, que age de maneira a manter relações ou práticas sexuais sem 0 consentimento da vítima e a violência psicológica, que se manifesta através de ameaças, insultos, e em que, muitas vezes, invertem-se os papéis, gerando uma culpabilização da vítima e tornando-a inferior são frequentemente "retratadas" tanto na vida real, sendo televisionada, noticiada, quanto na ficção, em obras literárias.

\section{O outro pé da sereia e a violência contra a mulher}

A mãe, serena, explanou: o assassínio, pensamos, nasce da torpeza da alma. Mas não: a vontade de matar nasce das miudezas do dia-adia, desse amarelecer sem história em que se convertem as nossas vidas. Não são os grandes traumas que fabricam as grandes maldades. São, sim, as miúdas arrelias do quotidiano, esse silencioso pilão que vai esmoendo a esperança, grão a grão (COUTO, 2006, p. 327-328).

Mia Couto nasceu em 1955, na cidade de Beira, Moçambique. É biólogo, jornalista e autor de mais de trinta livros, incluindo poemas, contos e romances. Sua estreia na literatura ocorreu em 1983, com o livro de poesia Raiz de orvalho. Seus livros já foram traduzidos em diversos idiomas, recebendo também diversos prêmios. Em 2013 recebeu o Prêmio Camões pelo conjunto da obra e o romance Terra sonâmbula é considerado um dos dez melhores livros africanos do século XX. Alguns de seus livros foram adaptados para o cinema, como $O$ último voo do flamingo, Terra sonâmbula e Um rio chamado tempo, uma casa chamada terra. Mia Couto, admirador da literatura brasileira, inclui em suas preferências literárias, nomes como Guimarães Rosa, Carlos Drummond de Andrade, João Cabral de Melo Neto e Adélia Prado, chegando a incluir epígrafes, em suas obras, de autores como Hilda Hilst.

A partir da independência do país, em 1975, Mia Couto trabalhou como diretor da Agência de Informação de Moçambique e foi coordenador da revista semanal Tempo e do jornal Notícias de Maputo, desenvolvendo, assim, um trabalho como jornalista. Na Universidade Eduardo Mondlane, em Moçambique, na década de 1980, cursou Biologia e se especializou em Ecologia. 


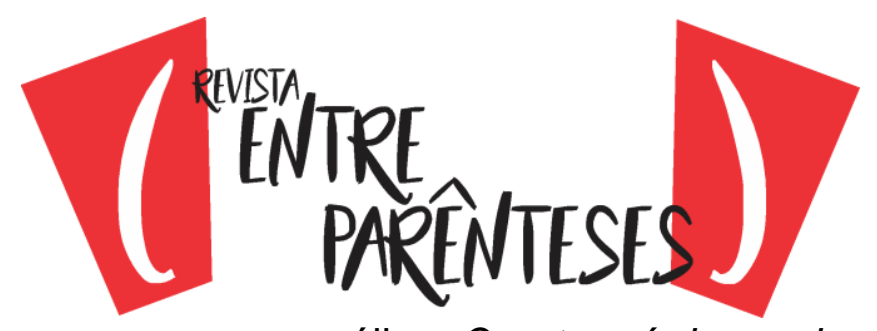

Sobre o romance em análise, $O$ outro pé da sereia, publicado inicialmente em Portugal, pelo Editorial Caminho, em 2006, é lançado no Brasil, no mesmo ano, pela Editora Companhia das Letras, mantendo a grafia vigente em Moçambique e mesclando com palavras de dialetos da população local. Com essa obra, Mia Couto recebeu, em 2007, o Prêmio Passo Fundo Zaffari \& Bourbon de Literatura.

No romance, Mia Couto reconstrói ficcionalmente um período da história de Moçambique, no passado, alternando histórias de um tempo presente. A expedição, comandada pelo jesuíta D. Gonçalo da Silveira, saía de Goa, na Índia, em 1560 com o objetivo de converter o imperador Monomotapa e o seu reino, situado hoje na fronteira entre Zimbabwe e Moçambique, e expandir o catolicismo em terras africanas. Nessa reconstrução ficcional da história, a narrativa apresenta uma retomada à colonização portuguesa, apresentando desde a travessia pelo oceano índico e a trajetória dos missionários pela África. Com capítulos que se alternam entre tempos diferentes, o romance apresenta, já no primeiro capítulo, a história de Mwadia Malunga e o marido Zero Madzero, que encontram, próxima ao rio que passa na aldeia de Antigamente, uma imagem de Nossa Senhora sem um dos pés. Os fatos que ocorrem na sequência são desencadeados em função deste acontecimento inicial, já que Mwadia recebe a missão de levar a estátua para a cidade de Vila Longe, a fim de encontrar um lugar que possa servir de abrigo para a imagem da santa. Lá, ela encontra uma comunidade que está em preparativos para a chegada de um casal, o americano Benjamin Southaman, que trabalha em uma ONG de ajuda à África e a esposa brasileira Rosie.

Composto por dezenove capítulos, o romance transita entre tempos distintos, ou seja, duas temporalidades, século XVI e século XXI, em uma separação estrutural que designa o espaço e a data explicados já no índice. No presente, há doze capítulos se passam em dezembro de 2002, em Moçambique. Um capítulo, chamado na narrativa como "Tempo indeterminado na atualidade", utiliza o recurso da analepse, remetendo a dois anos antes de 2002 - período em que a personagem Mwadia esteve estudando no Seminário de Darwin, em Zimbabwe. No passado, intercalam-se a estes, quatro capítulos que se passam em janeiro de 1560, um capítulo deles em Goa 


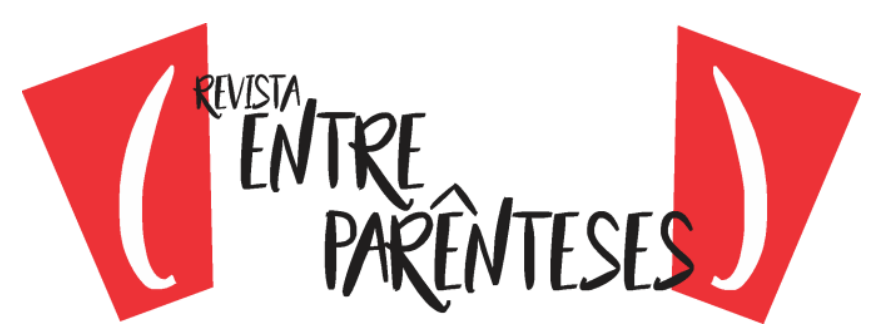

e três no Oceano Índico. No mesmo ano, com um salto de um mês, portanto, em fevereiro, há a presença de um capítulo que tem como espaço Moçambique. 0 penúltimo capítulo do romance apresenta um intervalo de tempo de mais de um ano, no período ainda em que a narrativa se passa no passado, e tem como ambiente geográfico as margens do rio Zambeze, em março de 1561.

Em relação ao narrador da história, a forma de apresentação se dá de modo a mostrar os fatos, colocando o leitor em contato direto com os acontecimentos e reproduzindo os diálogos das personagens em sua extensão, de forma direta. A voz que assume a narração é em terceira pessoa, com um narrador heterodiegético a partir de uma perspectiva onisciente.

Passado e presente se entrelaçam por algo em comum: a estátua encontrada na Moçambique do século XXI é a mesma carregada pela nau de $D$. Gonçalo da Silveira, a qual saiu de Goa, com destino à África, no século XVI. Mwadia, personagem principal, é quem interligará culturas e religiões em períodos históricos do passado e momentos do presente. $E$ é sobre essa personagem, e consequentemente o tratamento de outras, principalmente personagens masculinas, em relação à essa, que a análise será enfatizada. Além disso, focar-se-á no tratamento dado, não somente à Mwadia, mas às personagens mulheres da narrativa.

A mulher, como também em outras obras de Mia Couto, ganham um papel de destaque, ora de forma negativa, versando em questões de subalternidade e silenciamento, ora de forma positiva, sendo enaltecida, quando, por exemplo, na luta contra a opressão, surgem vozes femininas. Em O outro pé da sereia, as mulheres são constantemente lembradas das leis e tradições que imperam no território em que habitam. A mulher sendo colocada em um segundo plano e tendo de obedecer às normas de um sistema patriarcal. Apesar disso, Mwadia, uma das personagens principais se destaca, pois se torna encarregada de uma grande missão: encontrar um lugar protegido para abrigar a santa. É ela, também, que funciona como o elo entre passado e presente, ao dominar a escrita e ao fazer as leituras das cartas de D. Gonçalo, encontradas em um baú. Além disso, Mwadia também é chamada para servir de tradutora na chegada do casal na Aldeia vindo dos Estados Unidos. 


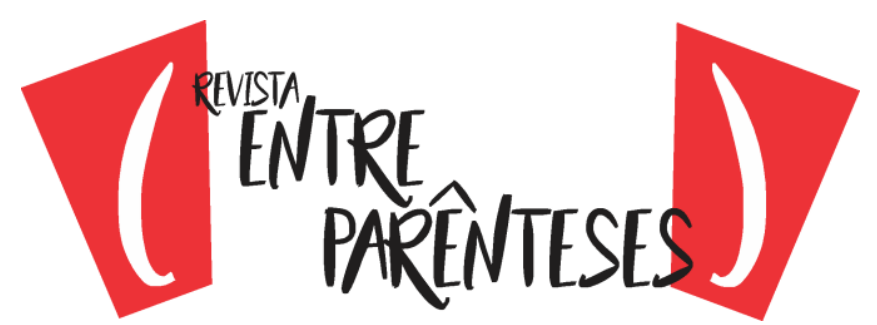

Porém, apesar da personagem principal ganhar um papel de destaque na narrativa, a violência de gênero, a submissão da mulher, o poder e o controle do homem sob o corpo feminino ainda são pulsantes nessa sociedade. Essa duplicidade da vida de Mwadia pode ser percebida na seguinte reflexão: "Mas a vida de Mwadia fez-se de contrassensos: ela era do mato e nascera em casa de cimento; era preta e tinha um padrasto indiano; era bela e casara com um marido tonto; era mulher e secava sem descendência" (COUTO, 2006, p. 69). Os sentimentos de Mwadia podem ser percebidos no seguinte excerto:

Longe da família, sem filhos, sem chuva, naquele canto para além do mundo, Mwadia não era nem a árvore nem a raiz de que falara Lázaro. Ela era um arbusto definhado e seco. Toda a morte tem o seu quê de suicídio. Mwadia, porém, já não se considerava vivente. Por isso, para deixar de viver, já nem carecia morrer (COUTO, 2006, p. 26).

Há a presença de várias formas de violência na narrativa. Em relação à violência de gênero, que tem como objetivo uma ordem social dos sexos, é possível encontrar vários tipos de agressões ao gênero feminino. Uma violência simbólica também pode ser apreendida como na seguinte passagem, em que o marido de Mwadia, Zero Madzero, trata a mulher como gente não-humana: "Só agora notava o quanto Ihe fazia falta conversar com gente humana. Não o palavrear ligeiro que, às vezes, destrocava com Mwadia. Mas conversa de macho para macho" (COUTO, 2006, p. 23). Ou ainda quando Zero Madzero trata a esposa como ninguém: "- Eu durmo sozinho. Mais do que sozinho, eu durmo com minha esposa" (COUTO, 2006, p. 25). Na passagem seguinte, pode ser percebida uma interdição, uma proibição da mulher de frequentar determinados espaços: "Sendo mulher ela está interdita de entrar no bosque" (COUTO, 2006, p. 34). Espaços interditos também à mãe, Constança, que tenta achar uma maneira para "driblar" esses percalços:

\footnotetext{
- Lembra-se do tempo em que eu passava tardes e tardes costurando?

- Lembro-me, mãe. Eram tantas filhas, tantas roupas!

- A maior parte das vezes, eu só fingia que costurava.

— Fingia? Fingia para quê?
} 


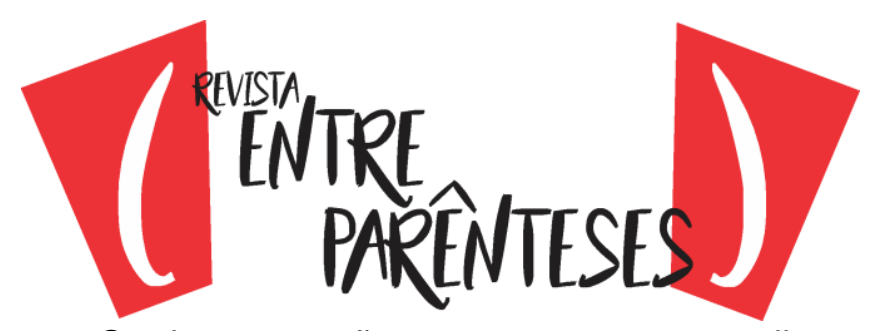

Os homens não gostam que as mulheres pensem em silêncio. Nascem-Ihes nervosas suspeitas.

- Enquanto ia costurando, o seu pai não imaginava que eu estava pensando. Minha cabeça viajava por todo lado.

Nesses escassos momentos, Constança era mulher sem ter que pedir licença, existindo sem ter que pedir perdão (COUTO, 2006, p. 78-79).

A condição masculina que normatiza a figura do "macho", "forte", "viril" e a mulher como ser "frágil" está enraizada em uma cultura patriarcal em que o homem visualiza a mulher, muitas vezes, como um ser controlável, sob dominação e posse. Esse comportamento do "macho" pode ser percebido no seguinte excerto, em relação ao personagem Zero Madzero: "Nenhum homem no mundo se envaidecia tanto de ser macho. Zero Madzero puxava lustro da tradição viril dos seus antepassados: os Chikundas, bravos caçadores de elefantes, intrépidos viajantes do rio, lendários guerreiros" (COUTO, 2006, p.20). Também se percebe esse comportamento em: "Depois, apressou o passo para que todos vissem que ele caminhava à frente da mulher, como era devido a um homem-macho. [...] E lá partiram, em silêncio. À frente, o pastor, depois, o burro e, por fim, a mulher" (COUTO, 2006, p. 26).

Uma das funções de Mwadia, como mulher e esposa, é dar banho no marido. Zero Madzero age como sendo essa função uma responsabilidade da mulher - atitude que carrega um certo preconceito e uma visão machista: "Tinha sido sempre assim: o pastor recusava banhar-se sozinho. Um homem fica menos macho se passeia as mãos pelo seu próprio corpo. Era essa a crença de Zero Madzero" (COUTO, 2006, p. 12).

Além disso a condição da mulher encontra-se no "esperar": "A mulher regressava à sua condição de esposa: retirou-se, convertendo-se em ausência. Lá fora, ela se dedicaria à sua mais antiga vocação: esperar" (COUTO, 2006, p. 22). Em alguns momentos há uma generificação sobre o comportamento feminino/masculino e uma normatização em relação ao que seria de comum e próprio ao homem e à mulher: "O dia seguinte foi o da partida de Mwadia. Sempre calado, o marido ajudoua a aparelhar o burro. Madzero também não disse palavra à despedida. Adeuses são assunto de mulheres" (COUTO, 2006, p. 45). 


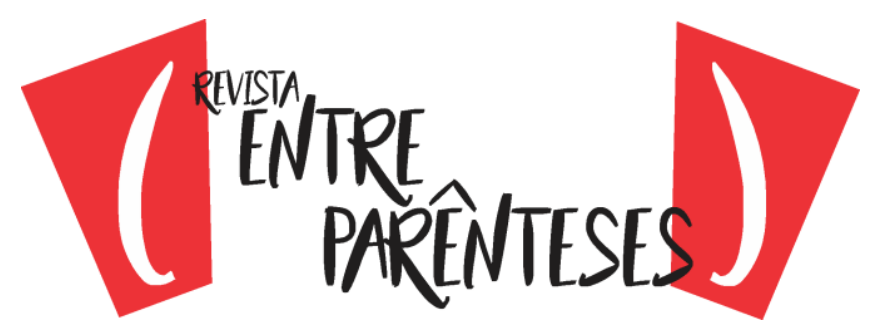

Sobre a violência física, as personagens femininas convivem com as agressões aos seus corpos, como na violência sofrida pela mãe de Mwadia, Constança, relatadas pelo pugilista e funcionário dos correios, Zeca Matambira:

- Sabe por que a sua mãe engordou tanto?, perguntou o pugilista. - Sim, ela me disse. Foi por causa da minha ausência.

Matambira sorriu, tristonhamente. A gente tem unha para não gastar o dedo. Às vezes, porém, é preciso cortar a unha para poupar o dedo. Isso disse Zeca Matambira como intróito para adocicar o que diria de seguida:

- Seu padrasto não parava de bater em Constança.

Começou quando Jesustino se dedicou à bebida. $\mathrm{O}$ álcool esboroou o miolo do alfaiate. E havia, suspeitava-se, razões de um desgosto de amor. Só isso poderia ter convertido em cruel azedume a antiga doçura do goês.

- Com mais carne, as pancadas doíam menos (COUTO, 2006, p. 322).

Já a violência sexual, quando se tem relações ou práticas sexuais sem o consentimento, pode ser encontrada nos abusos do padrasto Jesustino com Mwadia:

A enteada se ergueu para ajeitar as loiças na banca. Foi então que o padrasto se chegou, roçando-lhe o corpo. A moça reagiu, esquiva.

- Não tenha medo, minha filha.

- É tarde, eu já vou deitar-me.

- Tenha medo só dos que não viveram. Eu já vivi, já vivi de mais...

$\mathrm{O}$ alfaiate Jesustino Rodrigues virou costas, anunciando que ia tratar de descarregar o burro. A porta de rede bateu com estrondo atrás de si (COUTO, 2006, p. 72).

A violência psicológica é revisitava não somente quando está sendo empregada, mas continua atuando posteriormente, pois trata-se de uma agressão que tem como finalidade coibir, inibir, torturar, amedrontar com insultos, agressões verbais ou ainda ameaças. Em O outro pé da sereia, o padrasto de Mwadia, Jesustino, age de maneira a criar uma atmosfera de medo e de dominação em relação ao seu corpo, quando ele afirma que o filho que Mwadia espera é dele:

$\mathrm{Na}$ varanda, o alfaiate espreitou a confirmar que, àquela distância, Constança nada poderia escutar. De seguida, o homem falou atabalhoadamente:

- Devia ter-me dito primeiro, Mwadia. 


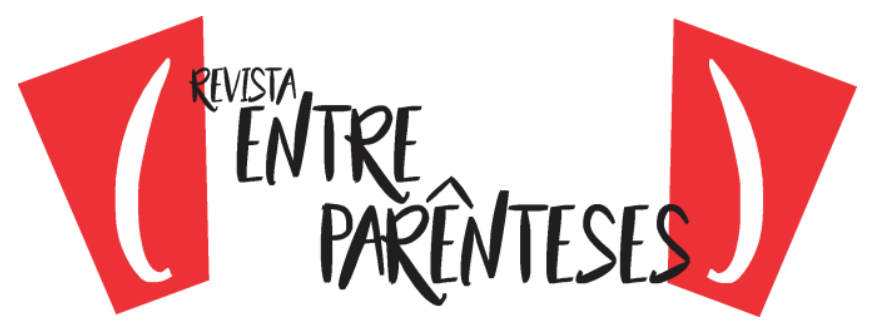

- E porquê?

- Porquê? Ora, minha filha, você está grávida de mim.

Os olhos de Mwadia abriram-se sem acerto. Ela não cabia em si [..] 0 alfaiate, porém, permaneceu impassível. [...]

- Esse filho é meu. Só pode ser meu.

- Seu? Como é possível?

Incrédula, Mwadia hesitava entre falar em português ou si-nyungwé. Para ela, naquele momento, toda a língua era estrangeira. A própria fala lhe era estranha e o padrasto tinha emigrado da razão.

- Padrasto, meu padrastinho. Por favor, não fale assim comigo.

- Esse filho é meu.

- Mas nós nunca estivemos juntos.

- Como nunca? (COUTO, 2006, p. 87).

Esse sistema de violência e opressões, dominação e posse está inserido em um contexto narrativo onde as mulheres devem prestar serviço aos homens. Aquelas inférteis ou incapacitadas de gerar um filho não são tratadas nem como mulheres. Em se tratando de personagens femininas, no romance, a maioria das passagens apresenta uma conformidade e uma aceitação por parte das mulheres, já que "o mundo é como é porque é como deve ser", como nas palavras de Giddens (2002, p. 50).

Em um mundo onde as mulheres em muitos momentos não encontram saída a não ser calar, resta o silenciamento. Especialmente em uma sociedade com tradições baseadas no patriarcalismo e em que comumente as mulheres são punidas e tratadas como seres inferiores, a insegurança e o medo tornam-se pulsantes.

\section{Considerações Finais}

No romance $O$ outro pé da sereia, de Mia Couto, há a presença de várias formas de violência. A partir dos pressupostos teóricos revisitados e da análise da obra atinge-se, assim, o objetivo proposto inicialmente. Os diferentes tipos de violência sofridos pelas mulheres podem ser encontrados claramente em passagens da narrativa, através de violências física, sexual, psicológica, simbólica e de gênero. 


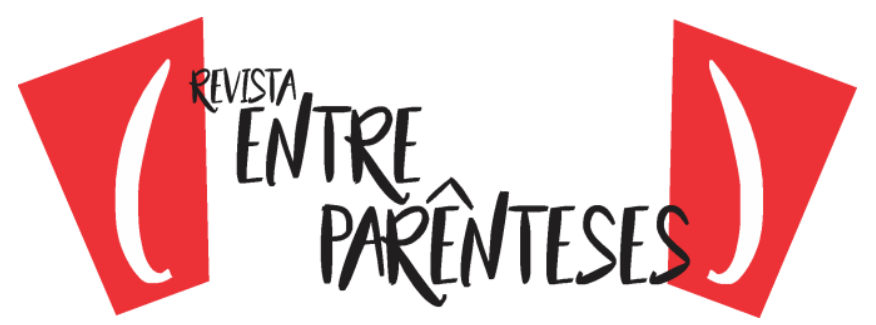

As violências sofridas tanto por Mwadia, quanto por Constança e por outras mulheres são manifestadas através de atos que são regidos pelo poder e/ou pela força. Na definição de violência por Bobbio, tem-se a seguinte prerrogativa:

Por Violência entende-se a intervenção física de um indivíduo ou grupo contra outro indivíduo ou grupo (ou também contra si mesmo). Para que haja Violência é preciso que a intervenção física seja voluntária [...]. Além disso, a intervenção física, na qual a Violência consiste, tem por finalidade destruir, ofender e coagir. [...] Exerce Violência quem tortura, fere ou mata; quem, não obstante a resistência, imobiliza ou manipula o corpo de outro; quem impede materialmente outro de cumprir determinada ação. Geralmente a Violência é exercida contra a vontade da vítima (BOBBIO, 2007, p. 1291).

A obra é permeada por passagens que trazem a mulher como papel de destaque, versada em questões de submissão, subalternidade, a partir de princípios, muitas vezes, normativos, naturalizados. Tem-se um universo representado e ficcionalizado à sua maneira, aproximando, em muitos momentos, de algo tão conhecido e discutido como a violência de gênero, a opressão e o silenciamento de vozes. Assim, as questões trabalhadas são pontos pertinentes e de extrema importância para a discussão atual a fim de compreender o tratamento dado à mulher em uma obra literária.

\section{Referências}

BHABHA, Homi K. O local da cultura. Belo Horizonte: UFMG, 2013.

BOBBIO, Norberto. et. al. Dicionário de política. Brasília: Ed. Univ. de Brasília, 2007.

BOSI, Alfredo. Literatura e resistência. São Paulo: Companhia das Letras, 2002.

BOURDIEU, Pierre. A dominação masculina: A condição feminina e a violência simbólica. Rio de Janeiro: BestBolso, 2016.

BUTLER, Judith. Problemas de gênero: Feminismo e subversão da identidade. Rio de Janeiro: Civilização Brasileira, 2016.

COUTO, Mia. O outro pé da sereia. São Paulo: Companhia das Letras, 2006. 


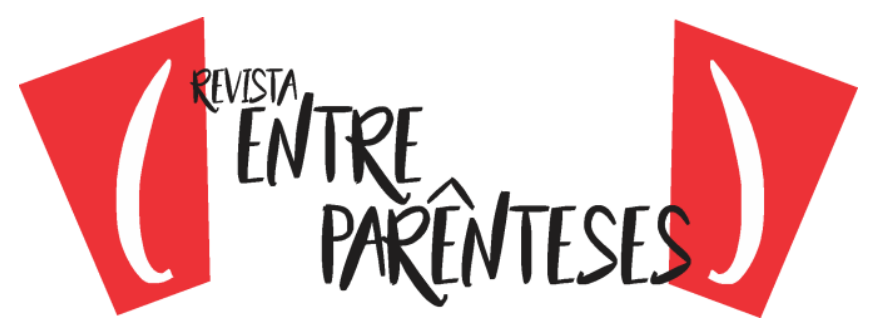

FOUCAULT, Michel. Vigiar e Punir. Rio de Janeiro: Vozes, 2012.

GIDDENS, Anthony. Modernidade e identidade. Rio de Janeiro: Zahar, 2002.

SAID, Edward W. Cultura e imperialismo. São Paulo: Companhia das Letras, 2011.

SOFSKY, Wolfgang. Tratado sobre la violencia. Madrid: ABADA, 2006.

TODOROV, Tzvetan. A literatura em perigo. Rio de Janeiro: DIFEL, 2010.

Recebido em: 10/05/2018

Aceito em: 21/11/2018 